\title{
PERCEPÇÃO DOS ALUNOS DE ENFERMAGEM SOBRE A FUNÇÃO ADMINISTRATIVA DO ENFERMEIRO *
}

\author{
Carlos Leonardo Angerami ** \\ Alessandra Mazzo **
}

\begin{abstract}
RESUMO - O exercıcıo profissional do enfermeiro apresenta contradições oriundas das divergências de padrões entre órgãos formadores e a prática desenvolvida nas unidades de saúde. Assim, ele é preparado para assistir diretamente ao paciente e a instituição empregadora tem a expectativa de que esse profissional assuma encargos administrativos. Preocupados com essa dicotomia entre o assistir e o administrar, os autores se propõem a averiguar a visão dos alunos do último ano de graduação em enfermagem sobre o trabalho administrativo do enfermeiro, bem como verificar sua percepção quanto ao seu preparo para exercer administração em enfermagem. $O$ estudo consta de um inquérito entre os referidos alunos, em duas escolas de Ribeirão Preto, onde buscamos conhecer as divergências entre o discurso acadêmico e a prática profissional do enfermeiro.
\end{abstract}

\begin{abstract}
The nurse's professional practice presents conflicts and contradictions due to divergence of standards between formative institutions and practice developed in health units. So, he is prepared directly to attend to patients and the employing institutions expect the profissionals to take on administrative responsabilities. Preoccupied with this dichotomy between assisting and administering, the authors propose to exame the perception of nursing undergraduate students envolled in the last year of the course, about this nurse's administrative function as well as to verify their perceptions as for the qualification to exercice administration in nursing. The study consists an inquiry by students from two colleges of Ribeirão Preto, where divergences is sought by academic speech and the nurse's profissional practice.
\end{abstract}

\section{INTRODUÇÃO}

O trabalho administrativo do enfermeiro é um assunto muito discutido entre os profissionais que atuam na prática assistencial e no ensino. Apesar de serem intensas as discussões e debates sobre esse assunto, parece-nos que a questão não está completamente compreendida no contexto da enfermagem. Observamos através da literatura e de depoimentos de profissionais, que há contradições inerentes a este trabalho e que o enfermeiro já ao se enga jar no seu primeiro emprego encontra-se frente à conflitos oriundos do seu preparo acadêmico versus exigências das instituições empregadoras.

Em outras palavras, os conflitos manifestam-se uma vez que, de modo geral, o enfermei- ro é preparado para dedicar-se à assistência direta ao paciente e a instituição que o emprega tem a expectativa de que este profissional assuma encargos administrativos. De acordo com RIBEIRO" "a maioria dos recém-diplomados tão logo recebe o diploma vê-se na contingência de tomar a si responsabilidades administrativa, de orientação e de supervisão de pessoal". Comentam ainda as autoras que "estudos recentes nos mostram que por longo tempo ainda essa situação irá perdurar, uma vez que a produção anual de nossas escolas não nos anima a pensar de outra maneira". Assim, em decorrência dessas contradições, fica evidente a comentada dicotomia entre o discurso acadêmico e a prática

* Prêmio Marina Andrade Rezende - 2o Lugar - 43 Congresso Brasileiro de Enfermagem - Curitiba-PR. 1991 - Trabalho orientado pela Professora Doutora Maria Auxiliadora Trevizan, Professor Associado da Escola de Enfermagem de Ribeirão Preto - USP, e coordenadora do Projeto "Problemática da utilização de recursos humanos no campo da Enfermagem"- CNPq

** Alunos do Curso de Graduação em Enfermagem - Escola de Enfermagem de Ribeirão Preto - USP, e Bolsista de Iniciação Científica junto ao $\mathrm{CNPq}$ 
profissional do enfermeiro.

Preocupações dessa natureza têm sido tratadas em nosso meio desde a década de 60 , por autores como: ALVIM e $\mathrm{Col}^{1}$, BAPTISTA ${ }^{2}$, BECKER e $\mathrm{Col}^{3}$, BURLAMAQUE ${ }^{4}$, FERREIRA SANTOS e MINZONI ${ }^{6}$, OLIVEIRA ${ }^{8}$, RIBEIRO $^{9}$, TREVIZAN ${ }^{11},{ }^{12},{ }^{13}$, CICONELLI e $\mathrm{Col}^{5}$.

Estes autores têm em comum a constatação de que o enfermeiro tem se dedicado ao desempenho de funções administrativas em porcentagem maior que as demais funções. RIBEIRO e $\mathrm{Col}^{9}$ já antevendo esta situação, em 1965 publica um programa de Administração Aplicada a Enfermagem para o curso de Graduação em Enfermagem, onde salientam que um ponto importante a ser destacado, é o preparo do enfermeiro para as funções de liderança aliado ao seu preparo para assistência direta ao paciente, enfatizando que as funções administrativas, sem dúvida, darão suporte necessário para a melhoria da assistência. Entendemos assim, que estas autoras procuram conciliar o preparo do enfermeiro tendo em vista as duas dimensões: $\mathrm{O}$ administrar e o assistir.

Analisando a função administrativa desse profissional à luz das implicações e das imposições do processo organizacional, TREVI$\mathrm{ZAN}^{12}$ evidencia que a atuação do enfermeiro é dependente de forças que acarretam a burocratização de seu trabalhoi e subordinação às exigências da administração hospitalar e de grupos profissionais que interferem de modo direto no trabalho da enfermagem. Concordamos com a autora quando discorda desta posição assumida pelo enfermeiro.

$\mathrm{Na}$ opinião de TREVIZAN ${ }^{12}$, a enfermeira "realiza-se como profissional fazendo uma administração que tenha como centro o cliente. Para isso é necessário que defina as metas de seu serviço e que a partir delas trace um planejamento, aceitando o desafio de converter o plane jamento em ação. Nesta ótica estão implícitas algumas atitudes por parte da enfermeira. Ela deve, em princípio, deixar de ser simples executora de tarefas ditadas por outros, ou por normas, assumir a auto-determinação de suas funções e ajustar princípios e medidas administrativas à solução de problemas específicos de sua área". Diante do exposto, acreditamos como a autora citada, que o exercício administrativo do enfermeiro, deva ser centralizado na assistência ao paciente. No entanto, como alunos sentimos necessidade de que este comportamento do enfermeiro seja mais explorado para que possa nortear todo o Curso de Graduação em Enfermagem. em outras palavras, por compartilharmos da idéia, acreditamos que a filosofia dé nossa formação acadêmica deva ser embasada por um referencial teórico-prático que contem- ple o exercício da função administrativa centrado na assistência ao paciente.

Assim, este trabalho tem o propósito de averiguar a visão dos alunos do último ano de Graduação em Enfermagem sobre o trabalho administrativo do enfermeiro, bem como verificar a percepção destes alunos quanto ao seu preparo para exercer administração em enfermagem.

\section{METODOLOGIA}

O trabalho foi realizado em duas escolas de enfermagem, uma pública e outra particular do Município de Ribeirão Preto.

Para ef eito de coleta de dados, foram incluídos no estudo $77,8 \%$ dos alunos do último ano de Graduação em Enfermagem (Habilitação em Enfermagem Médico-Cirúrgica e Habilitação em Enfermagem de Saúde Pública) da escola pública, e $71,4 \%$ dos alunos do último ano de Graduação em Enfermagem da escola privada.

Para a obtenção dos dados referentes à escola particular, tivemos um primeiro contato com a coordenadora do Curso de Enfermagem da referida Instituição, a quem expressamos os objetivos do trabalho e da qual obtivemos parecer favorável para sua realização. Em relação à escola pública, sentimo-nos à vontade para a coleta de dados, uma vez que pertencemos a seu corpo discente.

A elaboração do instrumento de coleta de dados foi fundamentada na literatura sobre administração em Enfermagem; é composto de cinco perguntas fechadas, com alternativas múltiplas e uma pergunta aberta, onde os sujeitos da pesquisa poderiam manifestar-se dando sugestões ou fazendo comentários a respeito das disciplinas de administração cursadas durante a Graduação.

Para compreensão do instrumento toma-se necessário definir os seguintes termos; segundo TREVIZAN ${ }^{12}$ :

Administraçāo da Assistência ao Paciente: "tem como centro o paciente, é orientado para a assistência e envolve o plane jamento, a direção, a supervisão e a avaliação das atividades desenvolvidas pelo pessoal auxiliar, visando $o$ atendimento das necessidades que os pacientes apresentam".

Administraçāo da Unidade: refere-se "àquela que limita as atividades administrativas à provisão, manutenção e controle de recursos materiais destinados ao bom funcionamento da unidade, e à distribuição de tarefas ao pessoal".

Funçōes Administrativas Burocráticas: "a função administrativa burocrática envolve a utilização do conhecimento técnico especializado sobre administração, obtido através de cur- 
sos especiais, e o seu exercício contribui para o alcance dos objetivos da organização. Ela é norteada pela imparcialidade e objetividade".

A coleta de dados foi efetuada no mês de novembro de 1990. O preenchimento do instrumento se processou de maneira individualizada, pelos próprios sujeitos que aceitaram colaborar com esta pesquisa. Durante o preenchimento do instrumento mantivemo-nos à disposição para esclarecimento de eventuais dúvidas.

\section{RESULTADOS E DISCUSSÃO}

Conforme mencionamos na metodologia os dados foram óbtidos através da aplicação de um instrumento aos alunos do último ano de graduação de duas escolas de Enfermagem, uma pública que no último ano of erece opções para Habilitação em Enfermagem Médico-Cirúrgica e Habilitação em Enfermagem de Saúde Pública, e outra privada cujo currículo objetiva a formação do enfermeiro generalista.

Os sujeitos que participaram da pesquisa são preponderantemente do sexo feminino; apenas $4 \%$ dos alunos da escola pública e $10 \%$ da escola privada são do séxo masculino.

A idade média dos sujeitos é de 24 e 27 anos, das escolas pública e privada, respectivamente.

Passaremos a expor os resultados evidenciando os dados relativos a cada questão formulada.

Ao perguntarmos a respeito do objeto de trabalho do enfermeiro, verificamos que para $60,5 \%$ dos sujeitos pesquisados este objeto se prende à administração da unidade. Para 23,7\%; a coordenação do pessoal de enfermagem constitui o objeto de trabalho do profissional em questão. A administração da assistência ao paciente é compreendida como tal para apenas $7,9 \%$ dos alunos envolvidos na pesquisa. Evidencia-se,ainda,que dos 10 alunos provenientes da escola privada, 2 acreditam que o objeto de trabalho do enfermeiro seja a administração da assistência ao paciente, enquanto que, dos 28 alunos da escola pública, apenas um referiu ser este seu objeto de trabalho. A administração da unidade como objeto de trabalho do profissional foi entendida por 5 alunos e por 18 alunos das escolas privada e pública, respectivamente. Portanto, entre os alunos das duas escolas houve divergências significativas em relação à administração da assistência ao paciente e administração da unidade como objeto de trabalho do enfermeiro.

$\mathrm{Na}$ distribuição de frequências das funções que tomam mais tempo do enfermeiro, por ordem de prioridade, segundo a opinião dos sujeitos da pesquisa, observamos a distribuição dessas funções em $1 \%$, 2 e 3 ㅇ lugares, com $81,6 \%$,
$50 \%$ e $29 \%$ dos sujeitos, respectivamente.

Ao indicarem as funçốes que tomam mais tempo do enfermeiro, 29 alunos $(76,3 \%)$ mencionaram em primeiro lugar as administrativas burocráticas e 2 alunos $(5,3 \%)$ apontaram a administração da assistência ao paciente. Como segunda opção, 8 alunos (21\%) referiram a orientação e supervisão do pessoal de enfermagem e 4 alunos $(10,5 \%)$ citaram a colaboração com outros profissionais. Quatro alunos $(10,5 \%)$ referiram em terceiro lugar as funções assistenciais, seguidas pelas funções de colaboração com outros profissionais mencionadas por três alunos $(7,9 \%)$. Sete alunos $(18,4 \%)$ assinalaram mais de uma alternativa sem indicar prioridade. As funções mais mencioradas foram: administrativas centradas no paciente com seis indicações e administrativas burocráticas com cinco.

Os resultados referentes a esta questão foram basicamente os mesmos para ambas as escolas; assim não se fez necessário apresentá-las de forma distinta para confronto. Perguntamos aos alunos se eles se sentem preparados para exercerem funções administrativas e em caso afirmativo que assinalassem o tipo de administração para o qual o seu preparo está voltado. Destes, $15,8 \%$ não se sentem preparados para as funções administrativas. Dos 32 (84,2\%) alunos que referiram sentir-se preparados, 24 (75,0\%) acreditam-se capacitados para administrar a unidade e a assistência ao paciente; 4 $(12,5 \%)$ se sentem aptos para administrar a assistência ao paciente e $4(12,5 \%)$ para administrar a unidade exclusivamente. Dessa maneira, passamos a investigar se os alunos sentem-se satisfeitos com o conhecimento adquirido nas disciplinas de administração cursadas durante a Graduação, verificando que $57,9 \%$ estavam satisfeitos com esse conhecimento e $42,1 \%$ insatisfeitos. Ao interrogarmos sobre o motivo dessa insatisfação, encontramos freqüências distintas entre as duas instituições, onde verificamos uma acentuada contradição de opiniões pois, para $52,6 \%$ dos alunos da escola pública, encontramos apenas $16,6 \%$ da escola privada que alegaram como motivo de insatisfação a dicotomia entre bloco teórico e bloco prático das referidas disciplinas, enquanto que, para $66,8 \%$ dos alunos da escola privada, apenas $26,4 \%$ da escola pública apontaram como motivo de insatisfação a insuficiência de tempo para incorporar os conhecimentos ministrados. Observamos que $32(84,2 \%)$ alunos mencionaram que sentem-se capacitados para as funções administrativas. No entanto, gostaríamos de salientar que $42,1 \%$ dos sujeitos referiram insatisfação quanto ao conhecimento adquirido nas disciplinas de administração durante a graduação das duas instituições em estudo. 
JOURDANI ${ }^{7}$ ao afirmar que os cursos de administração são inadequadas ao país, menciona que "as melhores escolas de administração do país não estão dando conta de preparar o tipo de administrador que os novos tempos exigem". No mesmo artigo, a referida autora salienta que alunos admitem que são mal formados e "avaliam de forma diferente o que a escola oferece. Mas concordam num ponto: o curso precisa de uma reestruturação". Também em nosso estudo, $42,1 \%$ dos alunos, como mencionamos, referiram insatisfação em relação ao conhecimento obtido nas disciplinas de administração. Assim, há concordância entre nossos resultados e os de JOURDANI'.

Ao afirmarmos que a expectativa do mercado de trabalho em relação ao desempenho do enfermeiro é relacionada a funções administrativas, procuramos saber se os alunos das referidas instituições concordavam ou não com a afirmação acima citada, e em caso positivo, que indicassem o tipo de administração que é esperada do mesmo. Por encontrarmos divergências de respostas nas duas instituições estudadas, passaremos a discutí-las separadamente.

Em relação à escola pública, verificamos que dos $89,3 \%$ dos alunos que concordam que o mercado de trabalho tem a expectativa de que o enfermeiro desempenhe funções administrativas, $15(60 \%)$ alunos acreditam que essa expectativa esteja voltada para a administração da unidade de enfermagem e 10 (40\%) alunos acreditam que o que se espera do profissional de enfermagem seja a colaboração direta com a administração superior do hospital, enquanto que, na escola privada, dos $50 \%$ dos alunos que - concordam com a referida afirmação, $3(60 \%)$ alunos acreditam que a mesma consista na administração da assistência ao paciente e 2 (40\%) alunos na administração da unidade de enfermagem.

Quando solicitamos que comentassem ou dessem sugestões sobre as disciplinas de administração cursadas, obtivemos as seguintes:

- Ampliação da carga horária e melhor distribuição entre conteúdos teórico e prático;

- Maior vinculação entre teoria e prática;

- Utilização do método pedagógico da problematização, buscando na vivência prática alicerce para compreensão da teoria;

- Enfatizar o exercício administrativo quando em atividades práticas das disciplinas, uma vez que tem ocorrido preocupação com o desenvol- vimento de técnicas' de enfermagem em detrimento do administrar;

- Atualização dos docentes frente às necessidades administrativas da profissão, estimulando os alunos a refletirem e analisarem criticamente a questão administrativa na enfermagem a nível teórico-prático, discutindo a interferência dos fatores sócio-político-econômicos que influenciam no sistema de saúde.

\section{CONCLUSÃO}

- Em relação ao objeto de trabalho do enfermeiro, a maioria dos alunos indicou ser a administração da unidade seguida pela coordenação do pessoal de enfermagem;

- Quanto às funções que tomam mais tempo do enfermeiro, os alunos indicaram em primeiro lugar as funções administrativas burocráticas, em segundo lugar a orientação e supervisão do pessoal de enfermagem e em terceiro as funções assistenciais;

- $84,2 \%$ dos sujeitos mencionaram que estão preparados para o desempenho administrativo, sendo que a maioria referiu estar capacitada para administrar a unidade e a assistência ao paciente;

- 57,9\% dos alunos sentem-se satisfeitos com o conhecimento adquirido nas disciplinas de administração e $42,1 \%$ sentem-se insatisf eitos;

- O motivo desta insatisfação com relação aos alunos da escola pública foi predominantemente a dicotomia entre bloco teórico e prático, enquanto que na escola privada a maioria dos alunos apontou o tempo insuficiente para incorporar os conhecimentos ministrados como fator de insatisfação;

$-78,9 \%$ dos alunos das duas instituições acreditam que a expectativa do mercado de trabalho visa a atuação do enfermeiro como administrador e a maioria da escola pública relata que esta administração deve ser direcionada para sua unidade, enquanto que a maioria da escola privada acredita que o mercado de trabalho espera que o enfermeiro administre a assistência ao paciente.

Concordamos com as sugestões dadas pelos sujeitos investigados pois acreditamos que a viabilidade dessas sugestões possa tomar possível um ensino administrativo que contemple as reais necessidades da enfermagem e de nossos pacientes, compreendida por nós como a administração da assistência ao paciente. 


\section{REFERÊNCIAS BIBLIOGRÁFICAS}

1 ALVIM, E.F. e Col. Pesquisa Operacional das atividades de enfermagem na Fundação S.E.S.P. Revista Brasileira de Enfermagem, 19 (4): 236-302, 1966.

2 BAP TIS TA, W.A. Contribuição ao estudo da assistência de enfermagem-análise de al guns fatores relacionados à administração em enfermagem que podem interferir na assistência ao paciente. Ribeirão Preto, Escola de Enfermagem de Ribeirão Preto - USP, 1979, 183p. Dissertaçấo de Mestrado.

3 BECKER, R.S. e Col. Pesquisa operacional sobre as atividades de enfermagem no Conjunto Sanatorial Raphael de Paula Souza. Revista Brasileira de Enfermagem, 24 (1 e 2): $56-63,1971$.

4 BURLAMAQUE, C.S. Estudo do desempenho do enfermeiro de um hospital de ensino em nível de unidade de internação. Porto Alegre, Universidade Federal do Rio Grande do Sul, 1981 Dissertação de Mestrado.

5 CICONELli e Col. Papéis e funções das enfermeiras do Hospital das Clínicas de Ribeirão Preto - USP, in $R e$ latório do II Seminário sobre Educação em Enfermagem. Escola de Enfermagem de Ribeirão Preto - USP. OPAS/OMS, 1970

6 FERREIRA SANTOS, C.A. , MINZONI, M.A. Estudo das atividades de enfermagem em quatro unidades de um hospital governamental. Revista Brasileira de Enfermagem, 21 (5): 396-443, 1968.

7 JOURDANI, S. Cursos de administração são inadequados ao país. Folha de São Paulo, 26.05.1991. 3 - 7.

8 OLIVEIRA, M.I.R. A enfermeira como coordenadora da assistência ao paciente. Salvador. Universidade de São Paulo, 1972, 87p. Tese de Doutoramento.

9 RIBEIRO, C.M. e col. Programa de administração aplicada à enfermagem. Revista Brasileira de Enfermagem, 1965, (1): 7-19.

10 RIBEIRO, C.M. A gestão administrativa da enfermagem integral nos serviços de saúde. Revista Brasileira de Enfermagem, 24 (1 e 2): 70-100, 1971.

11 TREVIZAN, M.A. Estudo das atividades dos enfermeiros chefes de unidades de internação de um hospital-escola. Ribeirão Preto. Escola de Enfermagem de Ribeirão Preto - USP, 1978 - 117p. Dissertação de Mestrado.

12 TREVIZAN, M.A. Enfermagem hospitalar : administraçāo e burocracia. Brasília: UNB, 1988.

13 TREVIZAN, M.A. e col. Focalizando o exercício administrativo no conjunto de funções do enfermeiro. Revista da Escola de Enfermagem da USP, São Paulo, 23 (1): 17-26, abr., 1989. 